\title{
Binding of Coumarin 334 with $\beta$-Cyclodextrin and with C-Hexylpyrogallol[4]arene: Opposite Fluorescence Behavior
}

\author{
Chandrasekaran Sowrirajan and Enoch Israel Vijayaraj Muthu Vijayan \\ Department of Chemistry, Karunya University, Coimbatore, Tamil Nadu 641 114, India \\ Correspondence should be addressed to Enoch Israel Vijayaraj Muthu Vijayan; drisraelenoch@gmail.com
}

Received 26 May 2013; Revised 19 August 2013; Accepted 22 August 2013

Academic Editor: Piotr Przybylski

Copyright ( 2013 C. Sowrirajan and E. Israel Vijayaraj Muthu Vijayan. This is an open access article distributed under the Creative Commons Attribution License, which permits unrestricted use, distribution, and reproduction in any medium, provided the original work is properly cited.

\begin{abstract}
We report here the structure of the host-guest complexes of Coumarin 334 (C334) with $\beta$-cyclodextrin ( $\beta$-CD) and with Chexylpyrogallol[4] arene (C-HPA) and the effect of acidity on the neutral-cation equilibrium of C334 in water and in the presence of the host molecules. The structures of the host-guest complexes are proposed on the basis of the change of fluorescence on the addition of $\beta$-CD or C-HPA to C334 and by 2D ROESY spectroscopy. Opposite fluorescence behaviors, that is, quenching of fluorescence in $\beta$-CD and enhancement of fluorescence in C-HPA are observed. Time-resolved fluorescence analysis is done for the complexation, and biexponential decay pattern is observed. The possible strong inclusion complexation with C-HPA is explained. The ground and the excited state $p K_{a}$ values for the protonation equilibrium of C334 in water and the difficulty of protonation in the presence of the host molecules are discussed.
\end{abstract}

\section{Introduction}

Being well-known laser dyes, with intriguing electronic and photonic properties suitable for many technological applications, Coumarin dyes have been extensively used to study the dynamics of several chemical and photochemical processes [1-6]. The photophysical behavior of Coumarin dyes is an active area of research [7-11]. The absorption and emission maxima of the aminocoumarins are very sensitive to the solvent polarity. Due to this property, many researchers have used aminocoumarin dyes as fluorescence probes in studying many physicochemical processes [12-15]. Multiwavelength laser sources, dye laser, have advantages such as low cost and high conversion efficiency $[16,17]$. Photophysical properties of Coumarin dyes have been extensively studied for the past several years [18-21]. Coumarin and its metabolites are nonmutagenic [22]. Coumarins have also been reported to have biomedical applications [23-25]. Coumarin 334 (C334), chemically known as 10-acetyl-2,3,6,7-tetrahydro- $1 \mathrm{H}, 5 \mathrm{H}, 11 \mathrm{H}$-1-benzopyrano[6,7,8-ij]quinolizin-11-one, is a laser dye with rigid structure which is a well-known fluorophore [26], and its structure is shown in Figure 1(a). Since, as mentioned above, Coumarin dyes offer room for the extensive study of their properties in various environments, and the properties of $\mathrm{C} 334$ have not been explored in the presence of confined space like cyclodextrin, we have chosen it for the present study.

Cyclodextrins, which are naturally occurring cyclo-oligosaccharides mainly containing 6 to 8 glucopyranose moieties $(\alpha-, \beta$-, and $\gamma$-cyclodextrin, resp.), provide space for molecular encapsulation since they have a hydrophobic inner cavity with a capacity to encapsulate small organic molecules [27-30]. These molecules are soluble in water due to the presence of primary and secondary hydroxyl groups to the exterior and also increase the water solubility of the corresponding host-guest complexes. Pyrogallol[4]arenes, a class of calixarenes containing pyrogallol units, form hexameric capsules in the solid state [31] as well as in solution in the presence of specific guests [32]. Cyclodextrins and calixarenes as host structures differ in some important aspects; that is, calixarenes are made of aromatic rings flexible at their connecting bonds and prone to flipping, whereas the glucopyranose units in cyclodextrins remain rigid. These host molecules encapsulating the guests need to be investigated in detail as the stoichiometry, the binding constant, and the mode of binding can decide various the physicochemical 


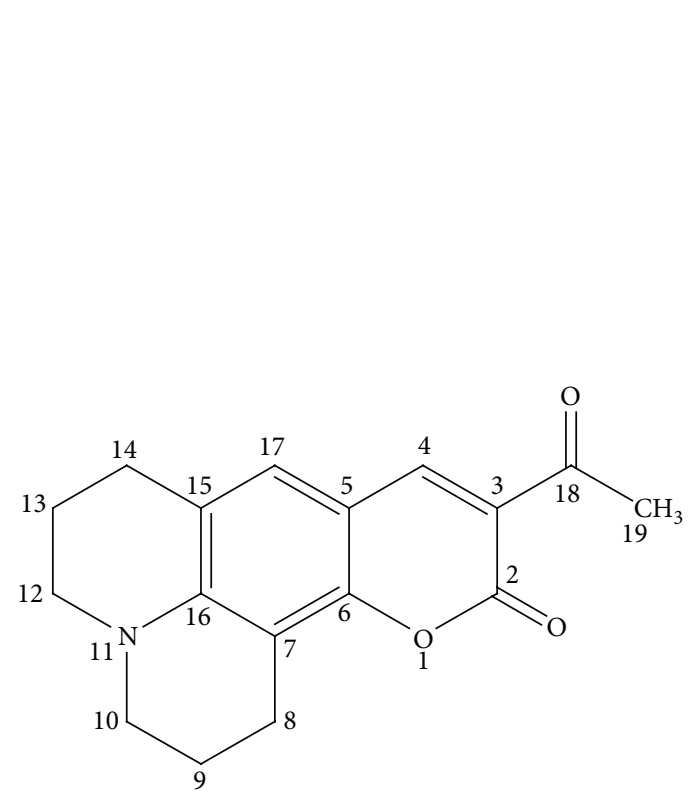

(a)

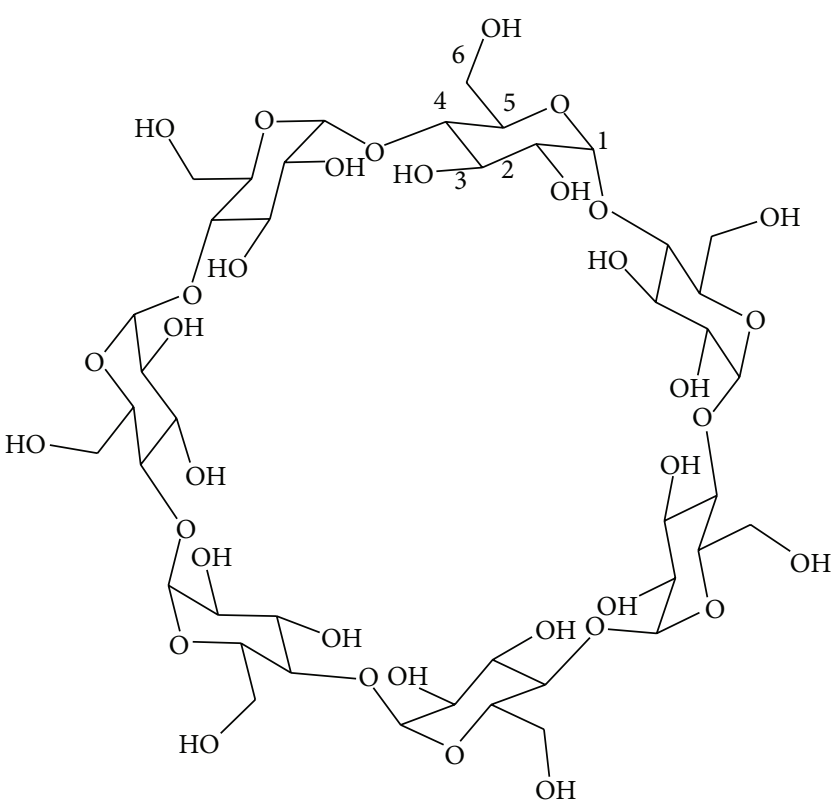

(b)

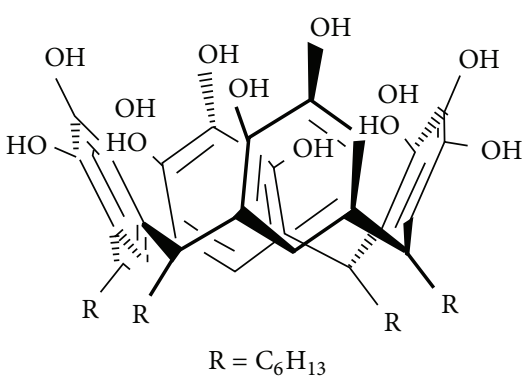

(c)

Figure 1: (a) Structure of C334. (b) Structure of $\beta$-CD. (c) Structure of C-HPA.

and the excited state properties of the guest molecules. The structural representation of $\beta$-cyclodextrin $(\beta-\mathrm{CD})$ and $\mathrm{C}$ hexylpyrogallol[4] arene (C-HPA) is given in Figures 1(b) and $1(\mathrm{c})$, respectively.

In this paper, we report (i) the stoichiometry and the strength of binding of C334 with $\beta$-CD and with C-HPA, (ii) the mode of binding of the guest with the hosts, and (iii) the effect of acidity on C334 and the influence of the molecular encapsulators on the prototropic equilibrium of C334. We used two-dimensional ROESY NMR spectroscopy [33] for characterizing the structure of the host-guest complexes of C334 with $\beta$-CD and C-HPA, the absorption spectroscopy, and the fluorescence spectroscopy for the understanding the mode and the strength of binding.

\section{Experimental}

2.1. Chemicals and Solvents. $\beta$-Cyclodextrin and Coumarin 334 were purchased respectively from Hi Media and SigmaAldrich and used as received. Phosphoric acid and sodium hydroxide, used for adjustment of $\mathrm{pH}$, were products of Qualigens. A modified Hammett's acidity scale [34] was used for the measurement of $H_{0}$ and $\mathrm{pH}$ below 2. CHexylpyrogallol[4]arene was prepared, by the reaction of heptaldehyde and pyrogallol (products of Sigma-Aldrich), following the literature procedure [34]. All the solvents used (Merck) were of spectral grade which were used as received.

\subsection{Preparation of C334- $\beta-C D$ and C334-C-HPA Solid Com-} plexes. C334 (0.35 g, $1.24 \mathrm{mmol})$ was dissolved in acetonitrile, and an equimolar amount of $\beta$-CD $(1.40 \mathrm{~g})$ was dissolved in doubly distilled water in $50 \mathrm{~mL}$ beakers separately. A solution of C334 was added slowly to the solution of $\beta$-CD at room temperature in an Ultra-sonicator and maintained for $30 \mathrm{~min}$. Then the mixture was warmed to $50^{\circ} \mathrm{C}$ for $10 \mathrm{~min}$ and kept at room temperature for two days. The solid obtained was collected and analyzed.

An equimolar amount of C334 $(0.3 \mathrm{~g}, 1.05 \mathrm{mmol})$ and CHPA $(0.94 \mathrm{~g})$ was dissolved in methanol in $50 \mathrm{~mL}$ beakers separately. A solution of C334 was added slowly to the solution of C-HPA at room temperature in an Ultra-sonicator and maintained for $30 \mathrm{~min}$. Then, the mixture was warmed to $50^{\circ} \mathrm{C}$ for $10 \mathrm{~min}$ and kept at room temperature for two days. The obtained solid was collected and analyzed. 
2.3. Preparation of Test Solutions. Test solutions were prepared by appropriate dilution from a stock solution of 1.7647 $\times 10^{-4} \mathrm{~mol} \mathrm{dm}^{-3}$ of $\mathrm{C} 334$. Owing to the poor solubility of C334 in water, the stock solution was made in methanol. The test solutions were having the concentration of methanol as $1 \%$. Stock solutions of the $\beta$-CD in the concentration of 1.2 $\times 10^{-2} \mathrm{~mol} \mathrm{dm}^{-3}$ and a stock solution of $2 \times 10^{-5} \mathrm{~mol} \mathrm{dm}^{-3}$ of CHPA were used for the preparation of test solutions. Various concentrations of sulfuric acid $(0.25,0.5,1.0,2.0$, 3.0 , and $4.0 \mathrm{~mol} \mathrm{dm}^{-3}$ ) were used to vary the acid strength, and $H_{0}$ values were interpreted from a modified Hammett's acidity scale. All reagents and solvents were of spectral grade which were used without further purification. Doubly distilled water was used throughout the experiments. All experiments were carried out at ambient temperature of $25 \pm$ $2^{\circ} \mathrm{C}$. The test solutions were homogeneous after all additives were added, and the absorption and the fluorescence spectra were recorded against appropriate blank solutions.

2.4. Instrumentation. Absorption measurements were performed with a double beam UV-visible spectrophotometer (Jasco-V 630) using $1 \mathrm{~cm}$ path length cells. A spectrofluorimeter (Perkin-Elmer LS55) equipped with a $120 \mathrm{~W}$ Xenon lamp for excitation served the measurement of fluorescence. Both the excitation and the emission bandwidths were set up at $4 \mathrm{~nm}$. Time-resolved fluorescence measurements were done on a time-correlated single photon counting spectrofluorometer (Jobin-Yvon IBH, Ti Saphhire Laser-Spectraphysics, LED Source: $470 \mathrm{~nm}$ ps-ns resolution). Ultra-sonicator PCI 9L $250 \mathrm{H}$, India, was used for sonication. $\mathrm{pH}$ studies were carried out using Elico LI $120 \mathrm{pH}$ meter, India. 2D ROESY spectra were recorded on a Bruker AV III instrument operating at $500 \mathrm{MHz}$ with DMSO- $\mathrm{d}_{6}$ as solvent for C334- $\beta$-CD complex and $\mathrm{CDCl}_{3}$ for C334-C-HPA complex. The chemical shift values are reported in ppm. Tetramethylsilane (TMS) was used as an internal standard. The chemical shift values were obtained downfield from TMS in part per million (ppm). The 2D ROESY experiments were performed on the prepared solid complexes of C334- $\beta-\mathrm{CD}$ and C334-C-HPA. The mixing time for ROSEY spectra was $200 \mathrm{~ms}$ under the spin lock condition.

\section{Results and Discussion}

3.1. The Study of Complexation of C334 with $\beta-C D$ or C-HPA. The absorbance spectra of $\mathrm{C} 334$ in the varying concentrations ( 0 to $1.2 \times 10^{-2} \mathrm{~mol} \mathrm{dm}^{-3}$ ) of $\beta$-CD are shown in Figure 2(a). The absorbance increases with the increase in the amount of $\beta$-CD with a marked and continuous red shift to a final $7 \mathrm{~nm}$. The absorbance and the fluorescence spectral data for the interaction of C334 with $\beta-\mathrm{CD}$ are given in Table 1 . This is quite opposed to the usual blue shift of absorbance on complexation with $\beta$-CD [30]. The blue shift is expected as the molecule dislodges from a polar solvent environment to the nonpolar cavity of $\beta$-CD when it forms an inclusion complex. The red shift we observe in the present case of C334 may be due to the surfactant action of $\beta$-CD on C334 surrounding and possibly forming hydrogen bonds with
TABLE 1: Absorption and fluorescence spectral data of C334 with various amounts of $\beta$-CD.

\begin{tabular}{lccc}
\hline $\begin{array}{l}\text { Concentration of } \\
\beta-\mathrm{CD}, \mathrm{mol} \mathrm{dm}^{-3}\end{array}$ & $\begin{array}{c}\text { Absorption } \\
\text { maximum, } \\
\mathrm{nm}\end{array}$ & $\begin{array}{c}\text { Absorbance, } \\
\text { a.u. }\end{array}$ & $\begin{array}{c}\text { Emission } \\
\text { maximum, } \\
\mathrm{nm}\end{array}$ \\
\hline 0 & 461.0 & 0.0638 & 503.0 \\
$1.0 \times 10^{-3}$ & 464.0 & 0.0637 & 504.0 \\
$2.0 \times 10^{-3}$ & 468.0 & 0.0655 & 504.0 \\
$8.0 \times 10^{-3}$ & 468.0 & 0.0717 & 504.0 \\
$1.0 \times 10^{-2}$ & 468.0 & 0.0783 & 504.0 \\
$1.2 \times 10^{-2}$ & 468.0 & 0.0832 & 504.0 \\
\hline
\end{tabular}

Excitation wavelength: $461 \mathrm{~nm}$.

it. The magnitude of red shift is significantly large as the C334 molecule itself is polar [35]. The absorbance increases indicating that sufficiently strong interaction between C334 and $\beta$-CD indeed occurs. The observed absorption spectral data were used in the following equation:

$$
\frac{1}{A-A_{0}}=\frac{1}{A^{\prime}-A_{0}}+\frac{1}{A^{\prime}-A_{0}} \frac{1}{K[\text { Host }]} .
$$

Here, $A_{0}$ is the intensity of absorbance of C334 in water, $A$ is the intensity of absorbance at the various concentrations of $\beta$-CD, $A^{\prime}$ is the intensity of absorbance at the highest concentration of $\beta-\mathrm{CD}$, and $K$ is the binding constant. The plot between $1 /\left(A-A_{0}\right)$ and $1 /[\beta-C D]$ is shown in Figure 2(b). The 1:1 stoichiometry was observed by the linearity in the plot with the correlation coefficient $(R)$ 0.9954, and the binding constant $(K)$ was calculated as $99.11 \mathrm{~mol}^{-1} \mathrm{dm}^{3}$.

Figure 2(c) shows the fluorescence spectra of C334 with varying amounts of $\beta-C D$ in solution. Upon the addition of $\beta$ $\mathrm{CD}$, the fluorescence of $\mathrm{C} 334$ is starting to get quenched and the quenching continues up to the maximum concentration of $\beta$-CD. This is quite opposite to the usual enhancement of fluorescence on $\beta$-CD complexation of fluorophores. Hence, the fluorophore may not form an inclusion complex. Moreover, the expected blue shift is not observed. Instead, we observe a $1 \mathrm{~nm}$ red shift (although weak). The Stern-Volmer plot [36] by using (2), made for the quenching of fluorescence of $\mathrm{C} 334$ by $\beta-\mathrm{CD}$, is shown in Figure 2(d). The quenching constant, $k_{Q}$, [37] is calculated from (3). The quenching constant was calculated as $4.66 \times 10^{9} \mathrm{~mol}^{-1} \mathrm{dm}^{3} \mathrm{sec}^{-1}$.

Consider the following:

$$
\begin{gathered}
\frac{F_{0}}{F}=1+K_{\mathrm{SV}}[Q], \\
k_{\mathrm{Q}}=\frac{K_{\mathrm{SV}}}{\tau_{f}},
\end{gathered}
$$

where $\tau_{f}$ is the lifetime of the quencher.

The time-resolved fluorescence profiles of C334 in the presence and absence of $\beta-C D$ are shown in Figure 3. Table 2 lists out the time-resolved fluorescence spectral data of C334 in the presence and absence of $\beta$-CD. The biexponential decay of C334 having $\tau_{1}(1.03 \mathrm{~ns})$ and $\tau_{2}(3.05 \mathrm{~ns})$ with relative 

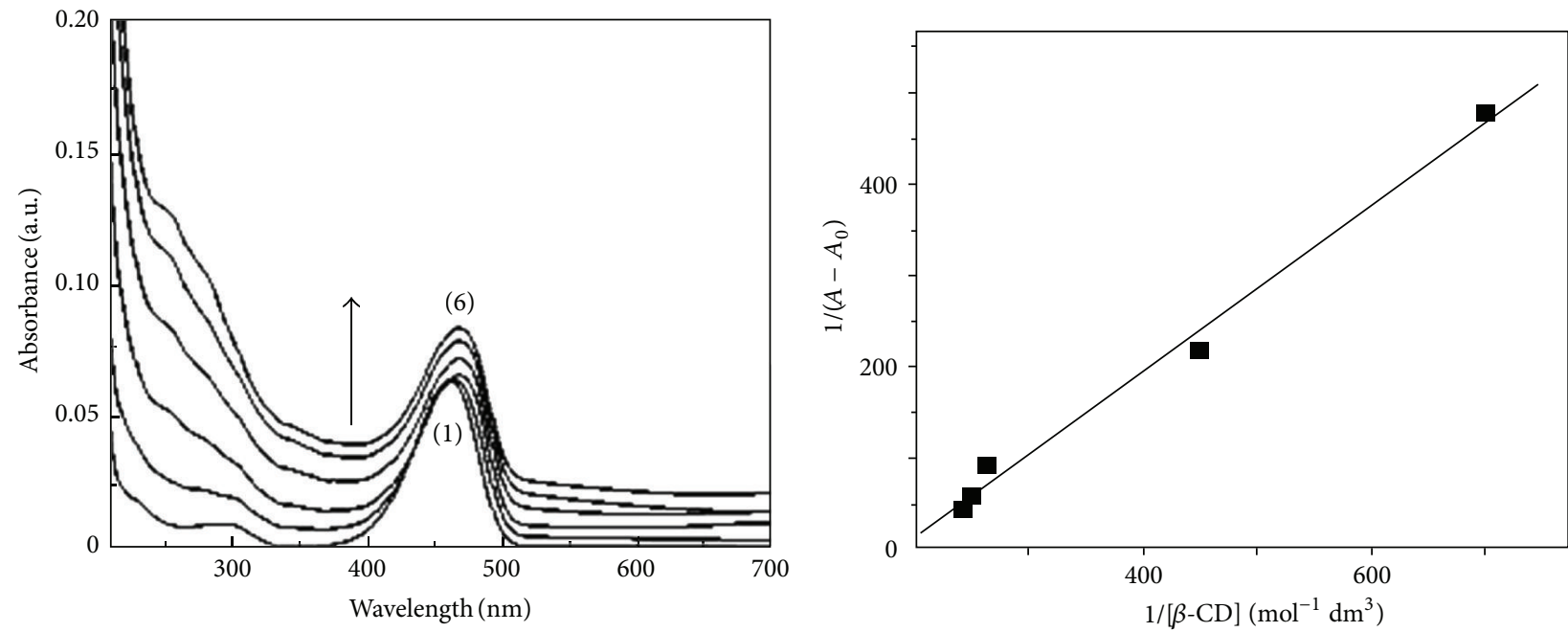

Concentrations of $\beta-\mathrm{CD}\left(\mathrm{mol} \mathrm{dm}^{-3}\right)$ :
(1) 0
(4) $8.0 \times 10^{-3}$
(2) $1.0 \times 10^{-3}$
(5) $1.0 \times 10^{-2}$
(3) $2.0 \times 10^{-3}$
(6) $1.2 \times 10^{-2}$

(a)

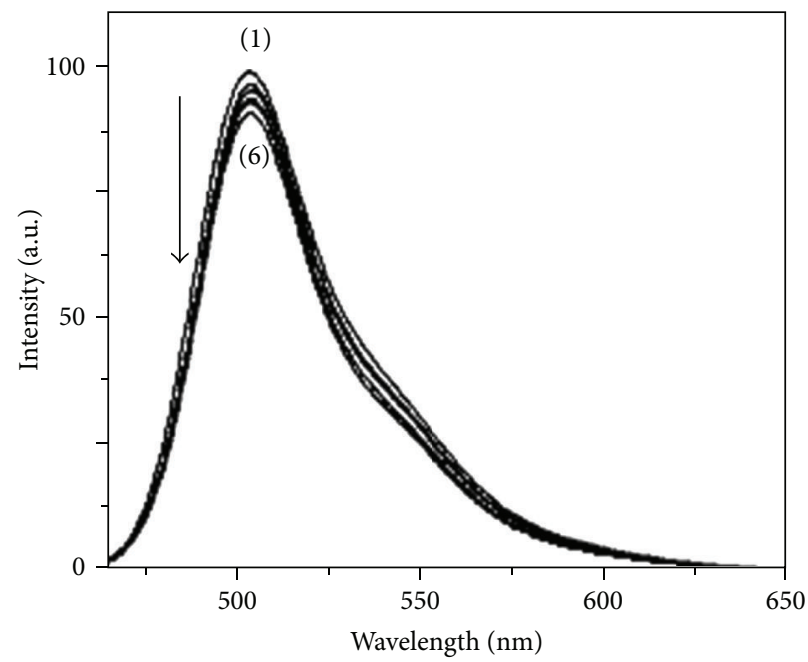

(b)

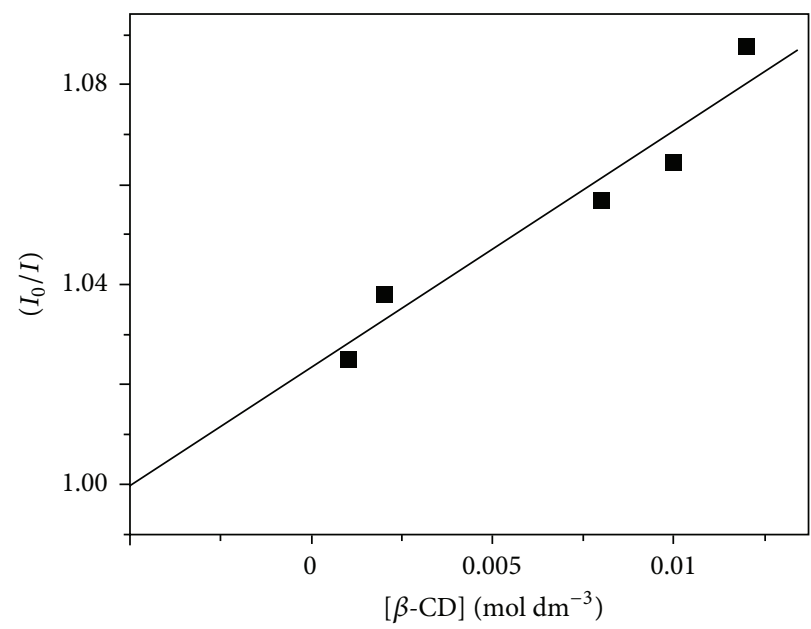

Concentrations of $\beta-\mathrm{CD}\left(\mathrm{mol} \mathrm{dm}^{-3}\right)$ :
(1) 0
(4) $8.0 \times 10^{-3}$
(2) $1.0 \times 10^{-3}$
(5) $1.0 \times 10^{-2}$
(3) $2.0 \times 10^{-3}$
(6) $1.2 \times 10^{-2}$

(c)

(d)

Figure 2: (a) Absorbance spectra of C334 with varying concentrations of $\beta$-CD. (b) $1 /\left(A-A_{0}\right)$ versus $1 /[\beta$-CD] plot of C334- $\beta$-CD complex. (c) Fluorescence spectra of C334 with varying concentrations of $\beta$-CD. (d) Stern-Volmer plot of C334- $\beta$-CD complex.

TABLE 2: Time-resolved fluorescence spectral data of C334 in water and in $\beta$-CD.

\begin{tabular}{lccccc}
\hline Concentration of $\beta$-CD, $\mathrm{mol} \mathrm{dm}^{-3}$ & Energy states & Lifetime (s) & Relative amplitude & $\chi^{2}$ & Standard deviation (s) \\
\hline \multirow{2}{*}{0} & $\mathrm{~T} 1$ & $1.03 \times 10^{-9}$ & 60.79 & $2.10 \times 10^{-11}$ & 1.14 \\
& $\mathrm{~T} 2$ & $3.05 \times 10^{-9}$ & 39.21 & 63.52 & $1.12 \times 10^{-11}$ \\
\hline \multirow{2}{*}{$1.0 \times 10^{-3}$} & $\mathrm{~T} 1$ & $1.16 \times 10^{-9}$ & 36.48 & 1.02 & $3.85 \times 10^{-11}$ \\
& $\mathrm{~T} 2$ & $3.57 \times 10^{-9}$ & $38 \times 10^{-11}$ \\
\hline
\end{tabular}

Excitation wavelength: $470 \mathrm{~nm}$.

Emission wavelength: $504 \mathrm{~nm}$. 
TABLE 3: ${ }^{1} \mathrm{H}$ NMR spectral data of $\beta$-CD, C334, and C-HPA.

\begin{tabular}{|c|c|c|c|c|c|c|}
\hline \multicolumn{2}{|c|}{$\beta-\mathrm{CD}$} & \multicolumn{3}{|c|}{$\mathrm{C} 334$} & \multicolumn{2}{|c|}{ C-HPA } \\
\hline $\begin{array}{l}\text { Position of } \\
\text { protons }\end{array}$ & $\begin{array}{c}\text { Chemical shift, } \\
\delta(\mathrm{ppm})\end{array}$ & Nature of protons & Position of protons & Chemical shift, $\delta$ (ppm) & $\begin{array}{l}\text { Nature of } \\
\text { protons }\end{array}$ & $\begin{array}{c}\text { Chemical shift, } \\
\delta(\mathrm{ppm})\end{array}$ \\
\hline $\mathrm{H} 3$ & 3.30 & Methyl protons & 21 & 2.62 & C-Hexyl chain & \\
\hline $\mathrm{H} 4$ & 3.33 & $\begin{array}{l}\text { Chromone } \\
\text { proton }\end{array}$ & $4-\mathrm{CH}$ & 8.35 & Methyl protons & 0.93 \\
\hline $\mathrm{H} 2$ & 3.56 & Aromatic proton & $17-\mathrm{CH}$ & 7.24 & $\begin{array}{l}\text { Methylene } \\
\text { protons }\end{array}$ & $1.28-1.45$ \\
\hline H6 & 3.60 & $\begin{array}{l}\text { Methylene } \\
\text { protons }\end{array}$ & 9 and 13 & 1.90 & $\begin{array}{l}\mathrm{CH} \text { in the linked } \\
\text { pyrogallol units }\end{array}$ & $2.21-2.28$ \\
\hline H5 & 3.64 & $\begin{array}{l}\text { Methylene } \\
\text { protons }\end{array}$ & 8 and 14 & 2.69 & & \\
\hline $\begin{array}{l}\text { Primary } \\
\text { hydroxyl }\end{array}$ & 4.46 & $\begin{array}{l}\text { Methylene } \\
\text { protons }\end{array}$ & 10 and 12 & 3.33 & Aromatic ring & \\
\hline $\mathrm{H} 1$ & 4.83 & & & & $\begin{array}{l}\text { Aromatic } \\
\text { protons }\end{array}$ & 7.49 \\
\hline $\begin{array}{l}\text { Secondary } \\
\text { hydroxyl }\end{array}$ & 5.68 and 5.74 & & & & $\begin{array}{l}\text { Hydroxyl } \\
\text { protons }\end{array}$ & $\begin{array}{c}6.86,6.90 \text {, and } \\
8.80\end{array}$ \\
\hline
\end{tabular}

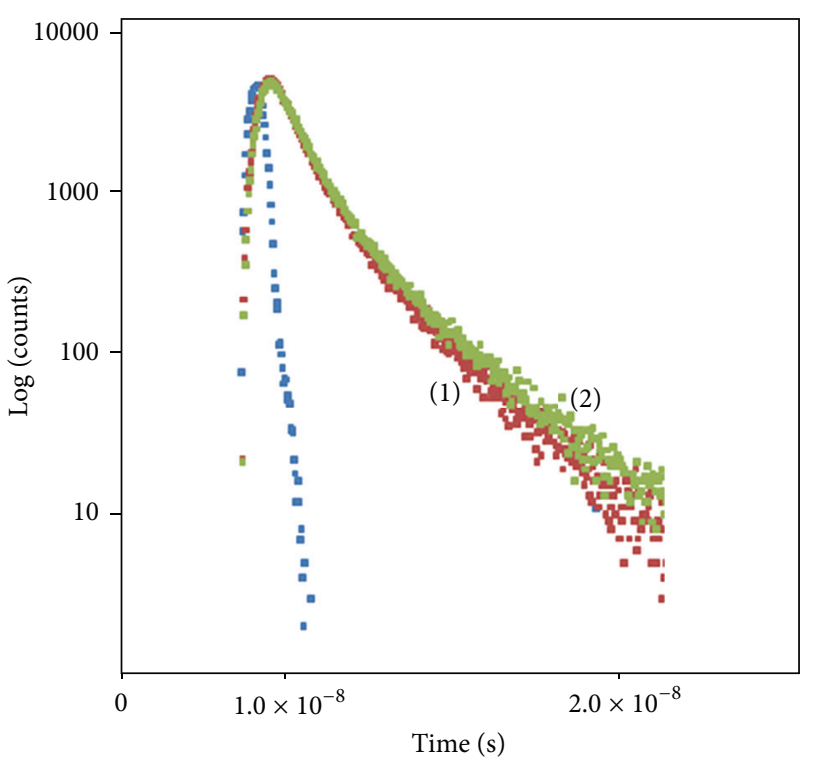

Concentrations of $\beta-\mathrm{CD}\left(\mathrm{mol} \mathrm{dm}^{-3}\right)$ :

(1) 0

(2) $1.0 \times 10^{-3}$

FIgURE 3: Time-resolved fluorescence spectra of C334 in $\beta$-CD.

amplitude 60.79 and 39.21 is not significantly altered upon the addition of $\beta$-CD; that is, the tri-exponential decay can be expected which, in this case, is not observed.

The ${ }^{1} \mathrm{H}$ NMR spectral values of $\beta$-CD, C334, and C-HPA are given in Table 3 . In the ${ }^{1} \mathrm{H}$ NMR spectrum of $\mathrm{C} 334$ $\beta$-CD inclusion complex, the $\mathrm{H} 4$ proton in the chromone ring resonates at $8.34 \mathrm{ppm}$. The aromatic proton of $\mathrm{C} 334$ resonates at $7.24 \mathrm{ppm}$. In the quinolizidine ring, the signals due to methylene protons of 10 and 12 which are attached to the tertiary nitrogen are observed at $3.30 \mathrm{ppm}$ which is

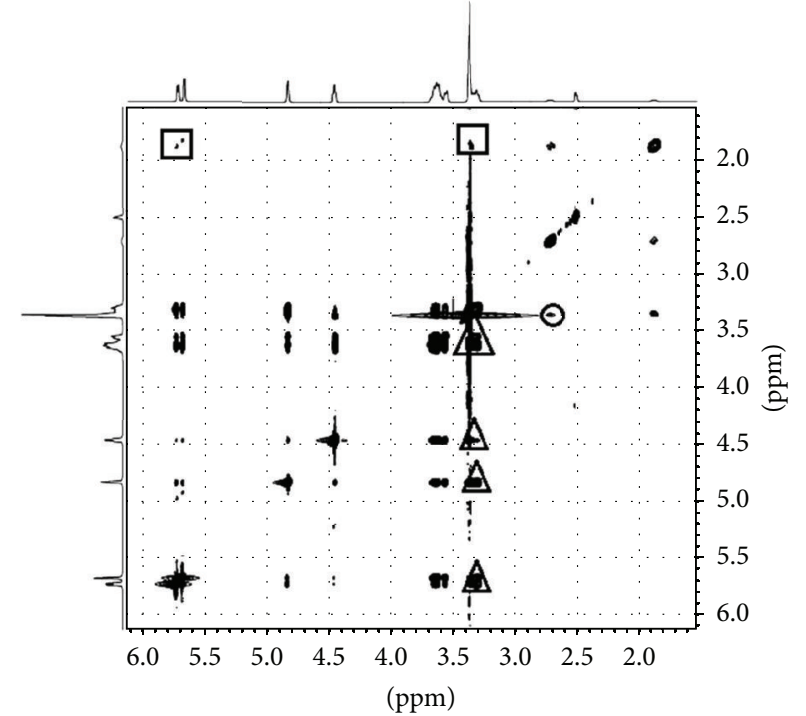

Figure 4: 2D ROESY NMR spectrum showing C334- $\beta$-CD complex.

very close to that of the $\mathrm{H} 4$ signal of $\beta-\mathrm{CD}$ at $3.33 \mathrm{ppm}$. The other methylene protons at positions 8 and 14 are deshielded to $2.71 \mathrm{ppm}$ as well as 9 and 13 protons observed upfield at $1.88 \mathrm{ppm}$.

Figure 4 shows the 2D ROESY NMR spectrum of C334- $\beta$-CD solid inclusion complex. There are cross peaks observed for the interaction of C334 methylene protons in hexahydroquinolizidine ring with the $\mathrm{H} 1, \mathrm{H} 4, \mathrm{H} 5$, and H6 protons and hydroxyl groups of $\beta$-CD. The cross peak indicated by the circle corresponds to the interaction of 8 and 14 methylene protons of $\mathrm{C} 334$ with $\mathrm{H} 4$ proton of $\beta$ CD. The cross peaks marked by the rectangle correspond to the 9 and 13 methylene protons of C334 interacting with the 

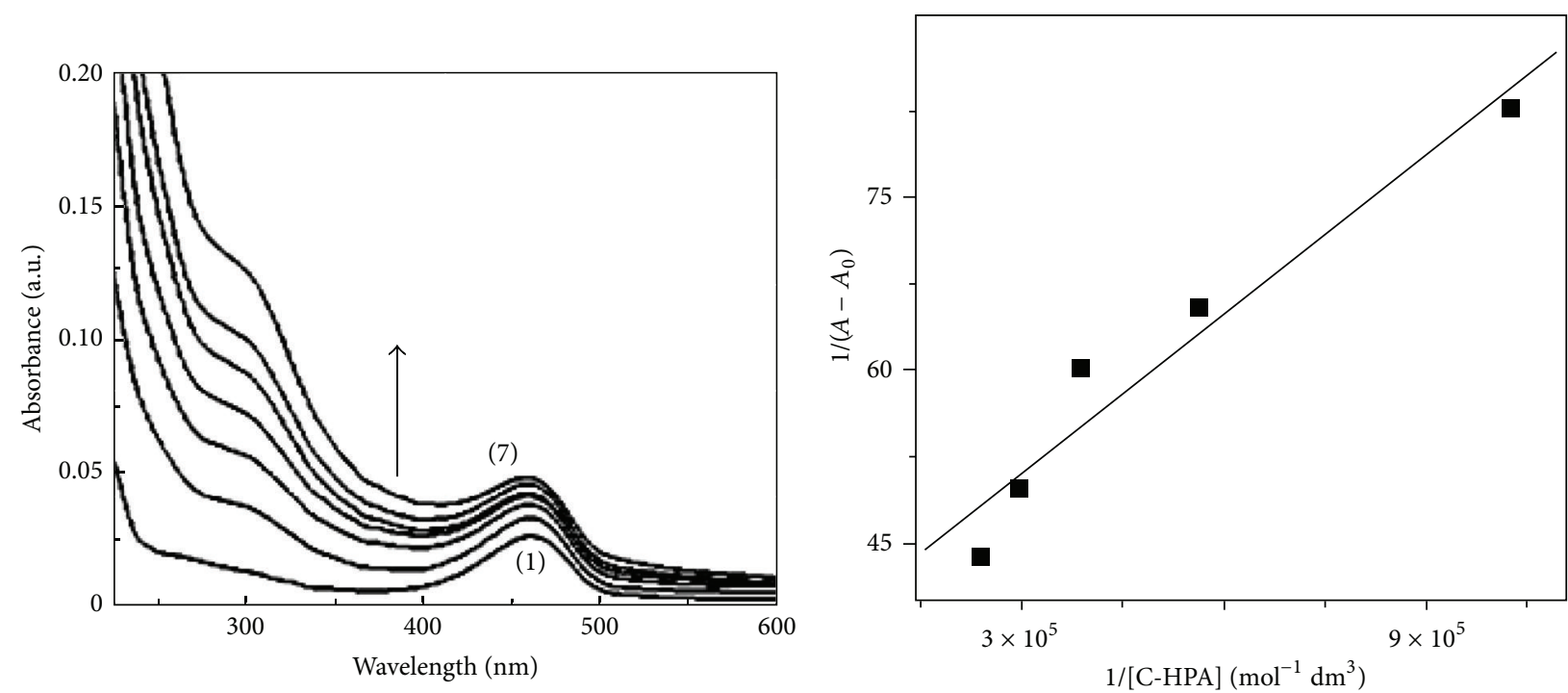

Concentrations of C-HPA $\left(\mathrm{mol} \mathrm{dm}^{-3}\right)$ :
(1) 0
(5) $2.58 \times 10^{-6}$
(2) $1.76 \times 10^{-7}$
(6) $3.38 \times 10^{-6}$
(3) $9.76 \times 10^{-7}$
(7) $4.16 \times 10^{-6}$

(4) $1.78 \times 10^{-6}$

(a)

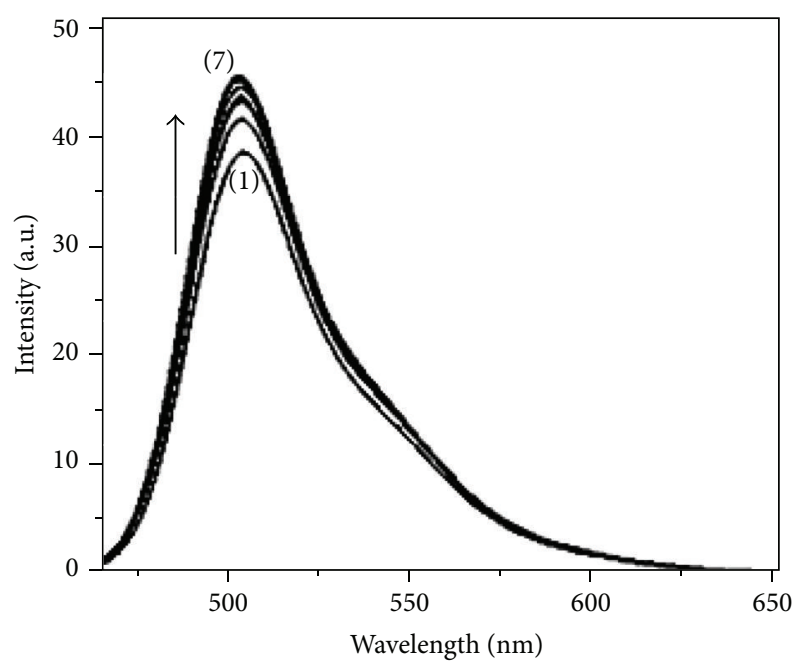

(b)

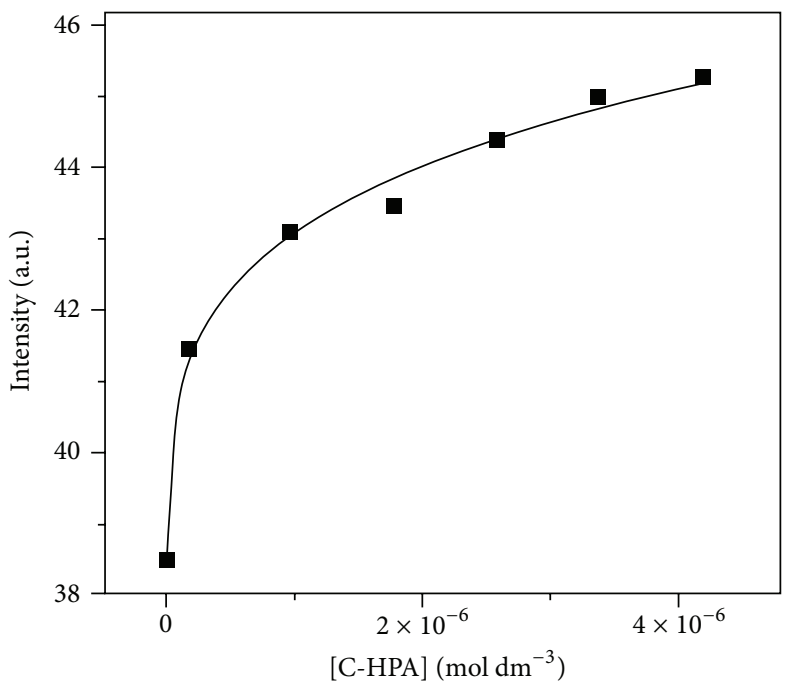

Concentrations of C-HPA $\left(\mathrm{mol} \mathrm{dm}^{-3}\right)$ :
(1) 0
(5) $2.58 \times 10^{-6}$
(2) $1.76 \times 10^{-7}$
(6) $3.38 \times 10^{-6}$
(3) $9.76 \times 10^{-7}$
(7) $4.16 \times 10^{-6}$
(4) $1.78 \times 10^{-6}$

(c)

(d)

Figure 5: (a) Absorbance spectra of C334 with varying concentrations of C-HPA. (b) $1 /\left(A-A_{0}\right)$ versus $1 /[\mathrm{C}-\mathrm{HPA}]$ plot of C334-C-HPA complex. (c) Fluorescence spectra of C334 at different concentrations of C-HPA. (d) Nonlinear plot for the increase in fluorescence intensity of C334-C-HPA complex. 
TABLE 4: Absorption and fluorescence spectral data of C334 with various amounts of C-HPA.

\begin{tabular}{lccc}
\hline $\begin{array}{l}\text { Concentration of } \\
\text { C-HPA, mol dm }\end{array}$ & $\begin{array}{c}\text { Absorption } \\
\text { maximum, } \\
\mathrm{nm}\end{array}$ & $\begin{array}{c}\text { Absorbance, } \\
\text { a.u. }\end{array}$ & $\begin{array}{c}\text { Emission } \\
\text { maximum, } \\
\mathrm{nm}\end{array}$ \\
\hline 0 & 462.0 & 0.0252 & 504.0 \\
$1.77 \times 10^{-6}$ & 461.0 & 0.0320 & 504.0 \\
$2.57 \times 10^{-6}$ & 460.0 & 0.0370 & 504.0 \\
$3.37 \times 10^{-6}$ & 460.0 & 0.0402 & 503.0 \\
$4.17 \times 10^{-6}$ & 460.0 & 0.0415 & 503.0 \\
$4.97 \times 10^{-6}$ & 460.0 & 0.0450 & 503.0 \\
$5.77 \times 10^{-6}$ & 459.0 & 0.0474 & 503.0 \\
\hline
\end{tabular}

Excitation wavelength: $461 \mathrm{~nm}$.

$\mathrm{H} 4$ proton and hydroxyl groups of $\beta$-CD. The H6, H5, and $\mathrm{H} 1$ protons of $\beta-\mathrm{CD}$ correlate with the 10 and 12 methylene protons of C334 (marked by a triangle) and the same protons cross-correlated with the primary hydroxyl groups of $\beta$-CD are denoted as the diamond symbol. From these correlation peaks, it is evident that the C334- $\beta$-CD interaction occurs with the hexahydroquinolizidine ring of C334 interacting with $\beta$-CD.

Figure 5(a) shows the absorption spectra of C334 with the increasing concentrations from 0 to $5.77 \times 10^{-6} \mathrm{~mol} \mathrm{dm}^{-3}$ of
C-HPA. The absorption spectral data are compiled in Table 4. The absorbance increases upon increasing the concentration of C-HPA. Additionally, a blue shift of $3 \mathrm{~nm}$ is observed in the absorption spectrum due to the influence of C-HPA. The blue shift is a characteristic of inclusion complexation with a hydrophobic cavity engulfing fluorophores. The 1:1 stoichiometry was observed from (1), and the linear plot is shown in Figure 5(b) with the correlation coefficient $(R)$ 0.97 , and the calculated binding constant $(K)$ was $9.5 \times$ $10^{5} \mathrm{~mol}^{-1} \mathrm{dm}^{3}$.

The fluorescence spectra of C334 in the presence of CHPA are shown in Figure 5(c). The fluorescence spectral data are given in Table 4. A fluorescence enhancement of C334 is observed at the addition of C-HPA, which is a result of complexation inside the cavity of the host molecule. Although it is less, a $1 \mathrm{~nm}$ blue shift is observed for the enhanced spectrum from the spectrum of C334 in water. The increase in the intensity of fluorescence on C334-C-HPA complexation is nonlinear, as shown in Figure 5(c) and the data are fit using a nonlinear curve fitting for the following equilibrium:

$$
G+H \rightleftarrows C,
$$

where $G$ represents C334 (guest), $H$ represents C-HPA (host), and $C$ refers to the inclusion complex. The binding constant $\left(K_{11}\right)$ for the $1: 1$ complex is determined as $1.6346 \times$ $10^{6} \mathrm{~mol}^{-1} \mathrm{dm}^{3}$ from the fitting of data in the following equation [38]:

$$
\Delta I=\frac{\Delta I_{11}\left\{\left(\left[G_{0}\right]+\left[H_{0}\right]+\left(1 / K_{11}\right)\right)-\sqrt{\left(\left[G_{0}\right]+\left[H_{0}\right]+\left(1 / K_{11}\right)\right)^{2}-4\left[G_{0}\right]\left[H_{0}\right]}\right\}}{2\left[G_{0}\right]},
$$

where $G_{0}$ is the initial concentration of guest, $H_{0}$ is the initial concentration of host, $K_{11}$ is the binding constant of the $1: 1$ complex, and $\Delta I_{11}$ is the intensity difference between the uncomplexed and complexed fluorophore. The binding curve for the C334-C-HPA binding is shown in Figure 5(d). This corresponds to a 1:1 stoichiometry of the guest and the host.

Figure 6 shows the time-resolved fluorescence decay of $\mathrm{C} 334$ in the presence and absence of C-HPA. The relative amplitude of the two states is altered on the complexation of C334 with C-HPA. The complex may not be influential enough to alter the excited states in a significant way; the time resolved spectral data are compiled in Table 5.

In ${ }^{1} \mathrm{H}$ NMR spectrum of C334-CHPA inclusion complex, the methylene protons (12 and 10) attached to the tertiary nitrogen is centered at $3.33 \mathrm{ppm}$ as multiplet. The methylene protons at the positions 8 and 14 resonate as triplets with the chemical shift of 2.75 and $2.85 \mathrm{ppm}$, respectively. The upfield shifted multiplet centered at $1.96 \mathrm{ppm}$ is assigned to the methylene protons of 9 and 13. The chromone proton resonates at $8.34 \mathrm{ppm}$, and the aromatic proton signal is observed at $7.46 \mathrm{ppm}$.

The cross peaks observed in the 2D ROESY NMR spectrum of C334-C-HPA inclusion complex are shown in Figure 7. The circle shows the correlation of methylene protons 8 and 14 present in the hexahydroquinolizidine ring with the aromatic proton of C-HPA. The aromatic proton at $\mathrm{H} 17$ of C334 correlates with the hydroxyl protons of C-HPA and are marked by a rectangle. Similarly, the same proton of $\mathrm{C} 334$ interacts with the $\mathrm{CH}$ proton in the phenyl rings linked position of C-HPA (which is marked by a triangle). The chromone proton (H4) of C334 correlates with the hydroxyls of C-HPA as shown by the diamond symbol. These correlation peaks suggest that the part of C334 binding with the C-HPA is the hexahydroquinolizidine part.

3.2. Effect of Acidity. Figure 8(a) shows the effect of $\mathrm{pH}$ on the absorption spectrum of $\mathrm{C} 334$ in water. Decrease of $\mathrm{pH}$ from 4.6 down to $H_{0}-1.85$ leads to a large blue shift of absorbance spectrum. The absorption band at $461 \mathrm{~nm}$ decreases in absorbance, and new bands are formed at $298 \mathrm{~nm}$ due to the formation of monocation of C334. This occurs at increased proton concentration. There is an isosbestic point at around $375 \mathrm{~nm}$ owing to the equilibrium between the neutral and the protonated forms of $\mathrm{C} 334$ concentration of neutral and protonated species at a given $\mathrm{pH}$. The protonation of the nitrogen of the quinolizidine moiety is likely involving the 
TABLE 5: Time-resolved fluorescence spectral data of C334 in C-HPA.

\begin{tabular}{|c|c|c|c|c|c|}
\hline $\begin{array}{l}\text { Concentration of } \\
\text { C-HPA, mol dm }\end{array}$ & Energy states & Lifetime (s) & Relative amplitude & $\chi^{2}$ & Standard deviation (s) \\
\hline \multirow{2}{*}{0} & $\mathrm{~T} 1$ & $1.03 \times 10^{-9}$ & 60.79 & \multirow{2}{*}{1.14} & $2.10 \times 10^{-11}$ \\
\hline & $\mathrm{T} 2$ & $3.05 \times 10^{-9}$ & 39.21 & & $4.12 \times 10^{-11}$ \\
\hline \multirow{2}{*}{$1.8 \times 10^{-7}$} & $\mathrm{~T} 1$ & $1.01 \times 10^{-9}$ & 64.32 & \multirow{2}{*}{0.10} & $1.93 \times 10^{-11}$ \\
\hline & $\mathrm{T} 2$ & $3.11 \times 10^{-9}$ & 35.68 & & $4.53 \times 10^{-11}$ \\
\hline \multirow{2}{*}{$3.4 \times 10^{-6}$} & $\mathrm{~T} 1$ & $9.43 \times 10^{-10}$ & 66.64 & \multirow{2}{*}{0.10} & $1.72 \times 10^{-11}$ \\
\hline & $\mathrm{T} 2$ & $2.86 \times 10^{-9}$ & 33.36 & & $3.94 \times 10^{-11}$ \\
\hline
\end{tabular}

Excitation wavelength: $470 \mathrm{~nm}$.

Emission wavelength: $504 \mathrm{~nm}$.

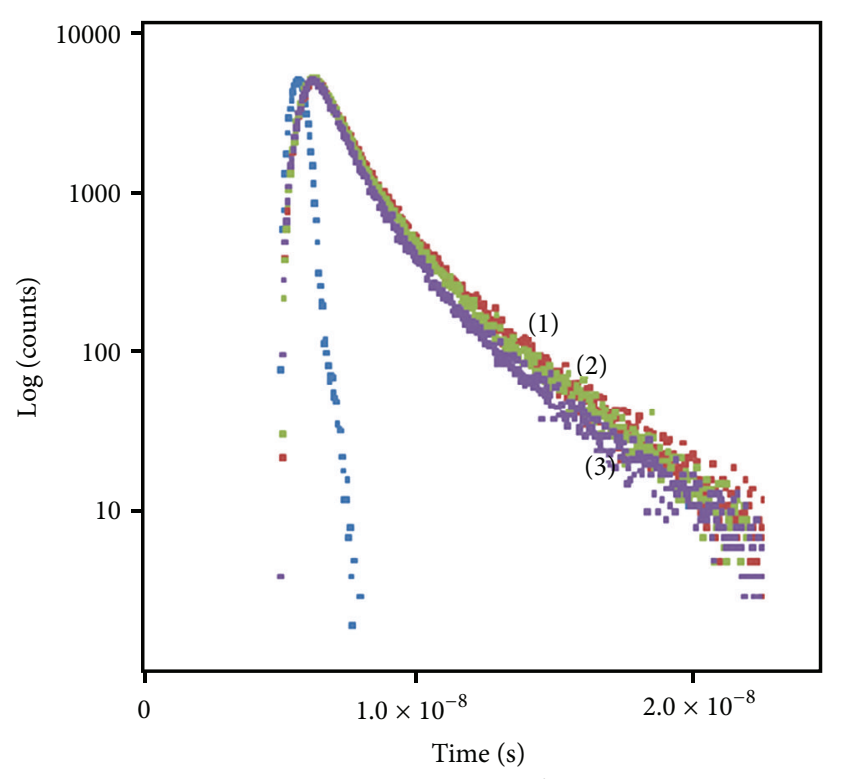

Concentrations of C-HPA $\left(\mathrm{mol} \mathrm{dm}^{-3}\right)$

(1) 0

(2) $1.8 \times 10^{-7}$

(3) $3.4 \times 10^{-6}$

FIGURE 6: Time-resolved fluorescence spectra of C334 in C-HPA.

lone pair of electrons on nitrogen. The ground state $p K_{a}$ value can be obtained for this equilibrium from [39]

$$
\begin{gathered}
C_{1}=\frac{A\left(\lambda_{1}\right) \varepsilon_{2}\left(\lambda_{2}\right)-A\left(\lambda_{2}\right) \varepsilon_{2}\left(\lambda_{1}\right)}{\varepsilon_{2}\left(\lambda_{1}\right) \varepsilon_{2}\left(\lambda_{2}\right)-\varepsilon_{1}\left(\lambda_{2}\right) \varepsilon_{2}\left(\lambda_{1}\right)}, \\
C_{2}=C_{T}-C_{1},
\end{gathered}
$$

where $C_{T}$ is the total concentration of the compound in both forms, and $\varepsilon_{1}\left(\lambda_{1}\right), \varepsilon_{2}\left(\lambda_{2}\right), \varepsilon_{2}\left(\lambda_{1}\right)$, and $\varepsilon_{2}\left(\lambda_{2}\right)$ are the molar extinction coefficients of the protonated and neutral forms at wavelengths $\lambda_{1}$ and $\lambda_{2}$, respectively (291 and $461 \mathrm{~nm}$ in this case). The $p K_{a}$ for the equilibrium of protonated-neutral forms is calculated using (8). The calculated $p K_{a}$ for the neutral-cation equilibrium of C334 in water is $0.42 \pm 0.03$.

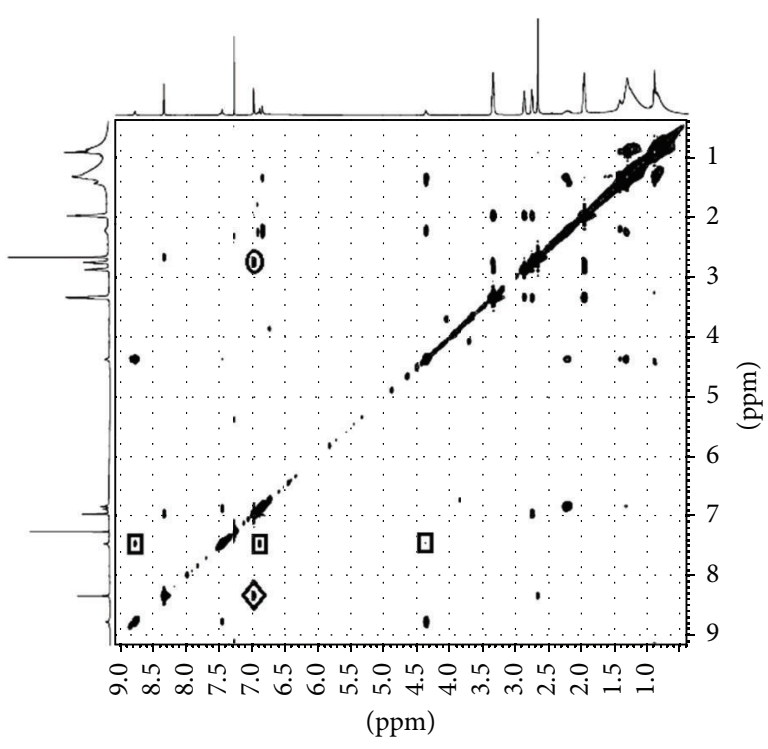

Figure 7: 2D ROESY NMR spectrum of the C334-C-HPA complex.

Consider the following:

$$
p K_{a}=\mathrm{pH}+\log \frac{C_{1}}{C_{2}} .
$$

The effect of $\mathrm{pH}$ on the absorption spectrum of C334 in $\beta$-CD is shown in Figure 8(b). Upon the decrease of $\mathrm{pH}$, the absorption at $465 \mathrm{~nm}$ indeed decreases with the corresponding increase of absorbance at $261 \mathrm{~nm}$ due to the formation of monocation. However, the isosbestic point is not met by all the spectra (at various $\mathrm{pH}$ ). The ground state $p K_{a}$ for the neutral-monocation equilibrium of C334 in the presence of $\beta$-CD is $0.35 \pm 0.03$. This is quite similar to the $p K_{a}$ value obtained for the same equilibrium in water.

Figure 8(c) shows the effect of C-HPA on the absorption spectrum of $\mathrm{C} 334$ over a range from $\mathrm{pH} 5.2$ to $H_{0}-1.85$. Decrease of absorbance from pH 5.2 is observed for the absorption band at $458 \mathrm{~nm}$ with a corresponding increase at $268 \mathrm{~nm}$. There is an isosbestic point at $400 \mathrm{~nm}$ indicating the equilibrium between neutral and protonated forms of C334. The ground state $p K_{a}$ for this equilibrium in the presence of C-HPA is determined as $0.37 \pm 0.03$. The slightly smaller 

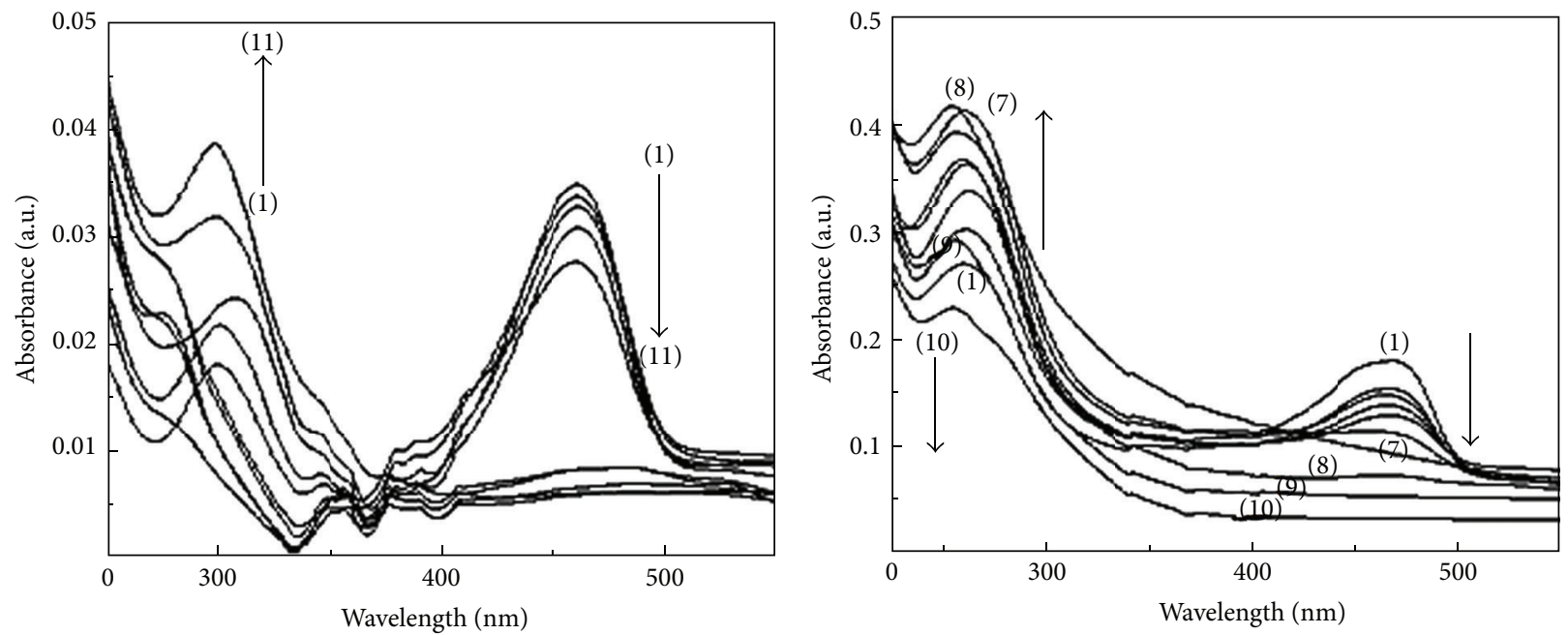
(1) $\mathrm{pH} 4.6$
(2) 2.6
(3) 2.2
(4) 1.8
(6) $H_{0} 0.44$

(7) $H_{0} 0.13$

(8) $H_{0}-0.26$

(9) $H_{0}-0.84$

(10) $H_{0}-1.38$

(11) $H_{0}-1.85$

(a)
(1) $\mathrm{pH} 7.0$
(6) $H_{0} 0.13$
(2) 6.4
(7) $H_{0}-0.26$
(3) 3.4
(8) $\mathrm{H}_{0}-0.84$
(4) 1.6
(9) $H_{0}-1.38$
(5) 1.0
(10) $H_{0}-1.85$

(b)

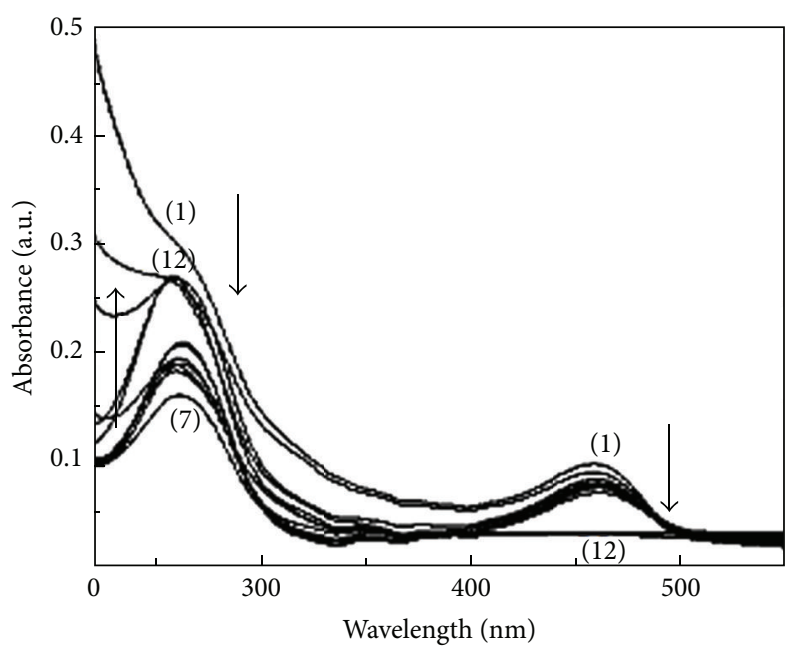
(1) $\mathrm{pH} 5.2$
(7) 1.0
(2) 4.7
(8) $\mathrm{H}_{0} 0.13$
(3) 4.0
(9) $H_{0}-0.26$
(4) 2.8
(10) $H_{0}-0.84$
(5) 2.2
(11) $H_{0}-1.38$
(6) 1.6
(12) $H_{0}-1.85$

(c)

Figure 8: (a) Absorbance spectra of $\mathrm{C} 334$ at various $\mathrm{pH}$ in water. (b) Absorbance spectra of $\mathrm{C} 334$ at various $\mathrm{pH}$ in $\beta$-CD. (c) Absorbance spectra of $\mathrm{C} 334$ at various $\mathrm{pH}$ in C-HPA. 


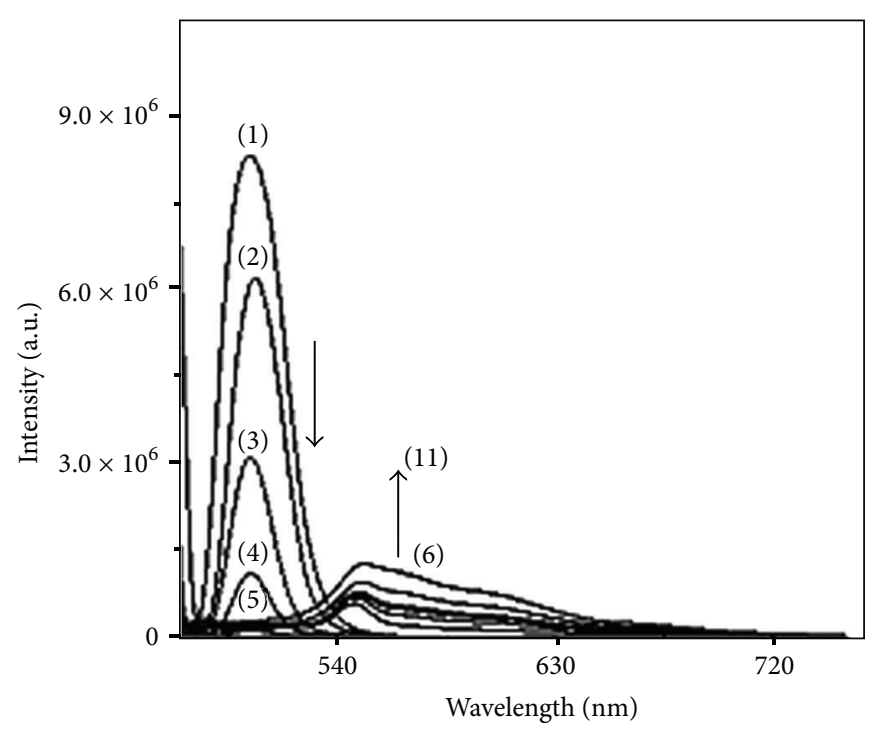
(1) $\mathrm{pH} 4.6$
(2) 2.6
(3) 2.2
(4) 1.8
(5) 1.4
(6) $H_{0} 0.44$
(7) $\mathrm{H}_{0} 0.13$
(8) $H_{0}-0.26$
(9) $H_{0}-0.84$
(10) $H_{0}-1.38$
(11) $H_{0}-1.85$

(a)

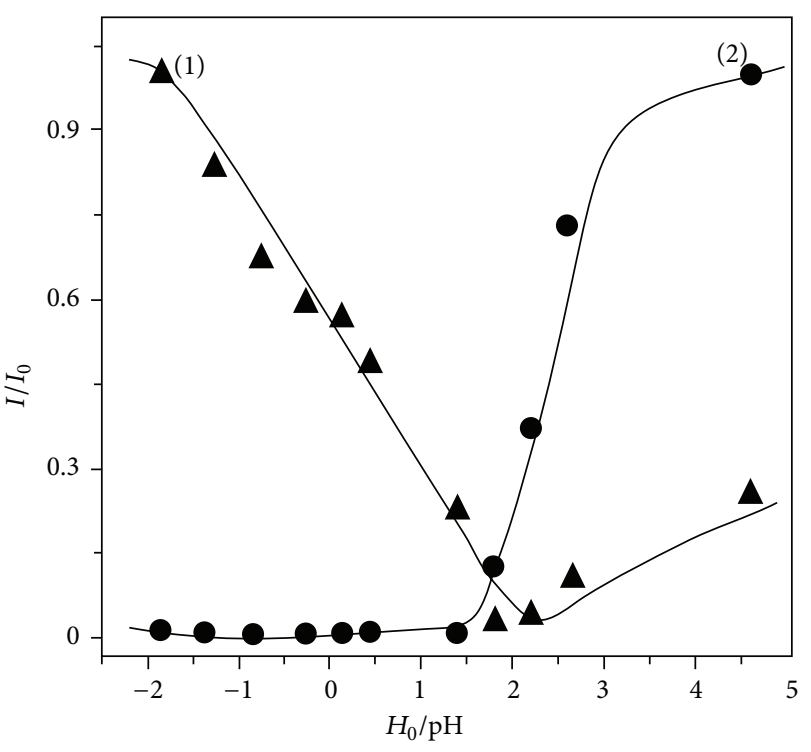

(1) Intensity: $546 \mathrm{~nm}$

(2) Intensity: $504 \mathrm{~nm}$

Figure 9: (a) Fluorescence spectra of $\mathrm{C} 334$ at various $\mathrm{pH}$ in water. (b) $I / I_{0}$ versus $H_{0} / \mathrm{pH}$ plot of $\mathrm{C} 334$ in water.

$p K_{a}$ value compared to that in water is due to the restricted environment offered by the host molecule for protonation.

The effect of $\mathrm{pH}$ on the fluorescence spectra of $\mathrm{C} 334$ in water is shown in Figure 9(a). The fluorimetric titration curves are shown in Figure 9(b). The fluorescence of C334 gets red shifted on protonation, that is, by increasing the acid concentration. There is quenching of fluorescence of the neutral form initially, and then there is start of appearance of a new band corresponding to the protonated form of C334. In the fluorimetric titration (FT) curve plotted using intensity at $504 \mathrm{~nm}$ there is a dip of relative fluorescence intensity. Then, the cation formation curve starts forming. Hence, an initial fluorescence quenching and then a cation formation are quite likely. The excited state $p K_{a}$ value, $\left(p K_{a}^{*}\right)$ for this equilibrium is obtained from the monocation formation curve as $0.4 \pm$ 0.03 . This value is close to the calculated ground state $p K_{a}$ value and this observation leads to the conclusion that the prototropic equilibrium is attained in the ground state itself and remain unaltered in the excited state.

The effect of $\mathrm{pH}$ on fluorescence of $\mathrm{C} 334$ in the presence of $\beta$-CD is shown in Figure 10(a). The bands corresponding to cation cannot be observed even at very high acidic conditions (less than $\left.H_{0}-1.85\right)$. The decrease in relative intensity of fluorescence is shown in Figure 10(b). The monocation formation may be hindered due to the pronounced hydrogen bonding interaction between the hydroxyls of $\beta-\mathrm{CD}$ and the fluorophore and hence the nonavailability of unshared pair of electrons for protonation.
The fluorescence spectra of $\mathrm{C} 334$ at various $H_{0} / \mathrm{pH}$ in the presence of C-HPA are shown in Figure 11(a). The fluorescence quenching curve is shown in Figure 11(b). The $p K_{a}^{*}$ cannot be calculated as the band corresponding to cation formation is not observed. Such an argument leads to the conclusion that the complexation of C-HPA hinders protonation of the guest molecule. Based on all the above arguments, the possible structure of the complexes of C334 with $\beta$-CD and with C-HPA can be represented as in Figures 12(a) and 12(b), respectively.

\section{Conclusions}

The enhancement in the absorbance spectrum of the C334$\beta$-CD complex was observed. The stoichiometry was determined as $1: 1$ from the linearity in the plot of $1 /(A-$ $A_{0}$ ) versus $1 /[\beta-\mathrm{CD}]$, and the binding constant was calculated as $99.1080 \mathrm{~mol}^{-1} \mathrm{dm}^{3}$. C334 showed a fluorescence quenching when it interacted with $\beta$-CD. The quenching constant $\left(K_{Q}\right)$ was calculated as $4.66 \times 10^{9} \mathrm{~mol}^{-1} \mathrm{dm}^{3} \mathrm{sec}^{-1}$. The C334- $\beta$-CD interaction occurred probably with the hexahydroquinoline ring of $\mathrm{C} 334$ interacting with $\beta$-CD. Quite contrarily, a fluorescence enhancement of C334 was observed for the interaction of C-HPA, which is a result of host-guest complexation. The increase in the intensity of fluorescence on C334-C-HPA complexation was nonlinear. The stoichiometry of the host: guest complex was $1: 1$ with 


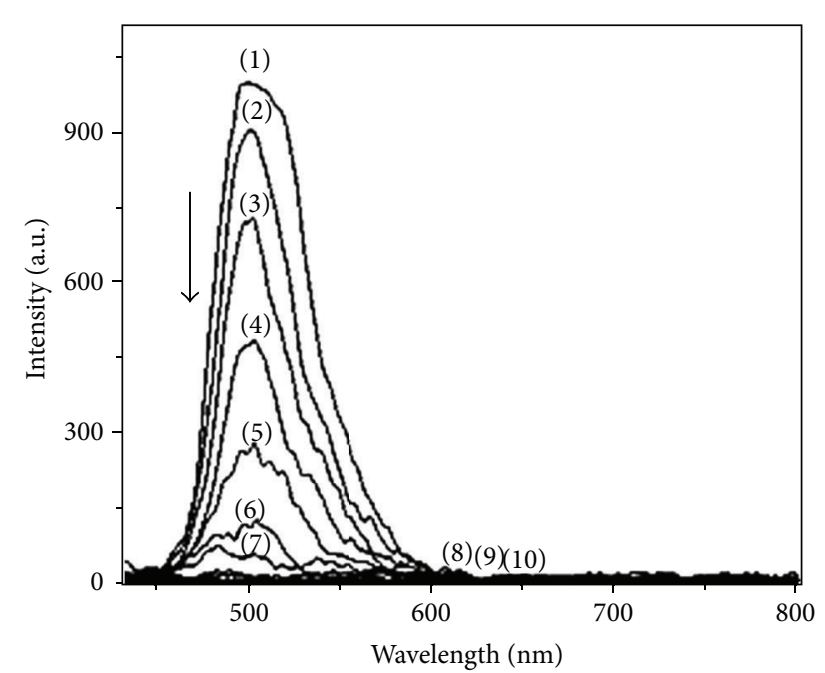
(1) $\mathrm{pH} 7.0$
(2) 6.4
(3) 3.4
(4) 1.6
(5) 1.0
(6) $H_{0} 0.13$
(7) $H_{0}-0.26$
(8) $\mathrm{H}_{0}-0.84$
(9) $H_{0}-1.38$
(10) $H_{0}-1.85$

(a)

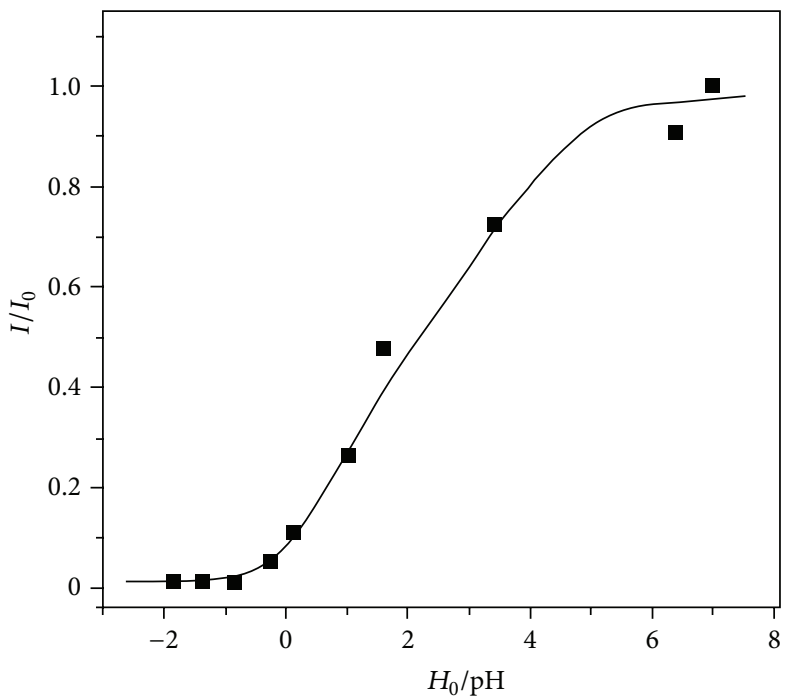

Intensity: $500 \mathrm{~nm}$

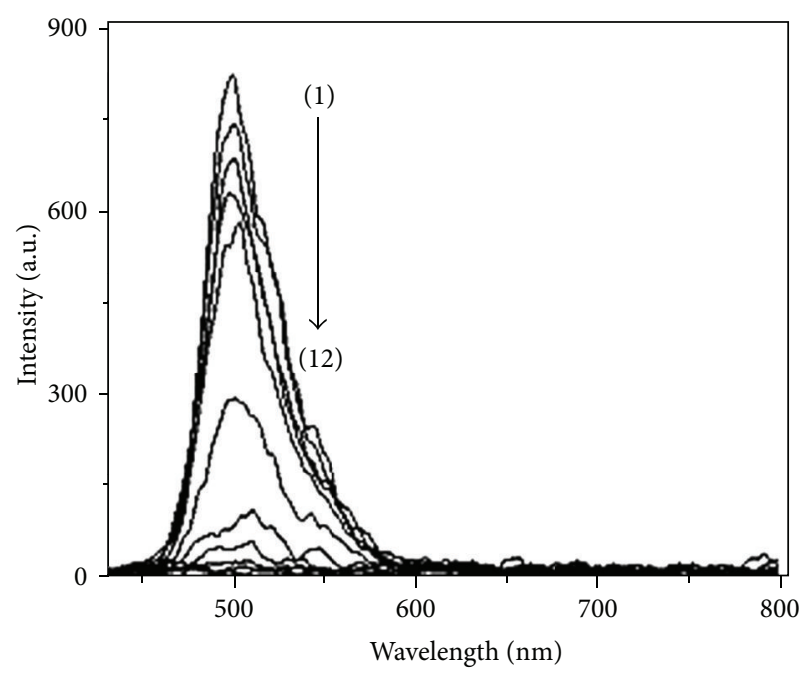
(1) $\mathrm{pH} 5.2$
(7) 1.0
(2) 4.7
(3) 4.0
(4) 2.8
(5) 2.2
(6) 1.6
(8) $H_{0} 0.13$
(9) $H_{0}-0.26$
(10) $H_{0}-0.84$
(11) $H_{0}-1.38$
(12) $H_{0}-1.85$

(a)

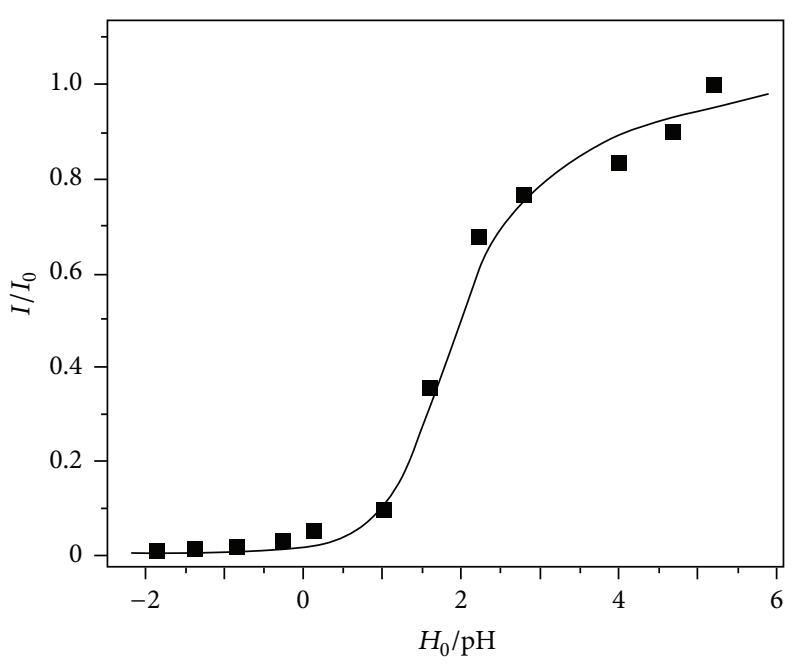

Intensity: $500 \mathrm{~nm}$

(b)

plot of C334 in $\beta$-CD. 


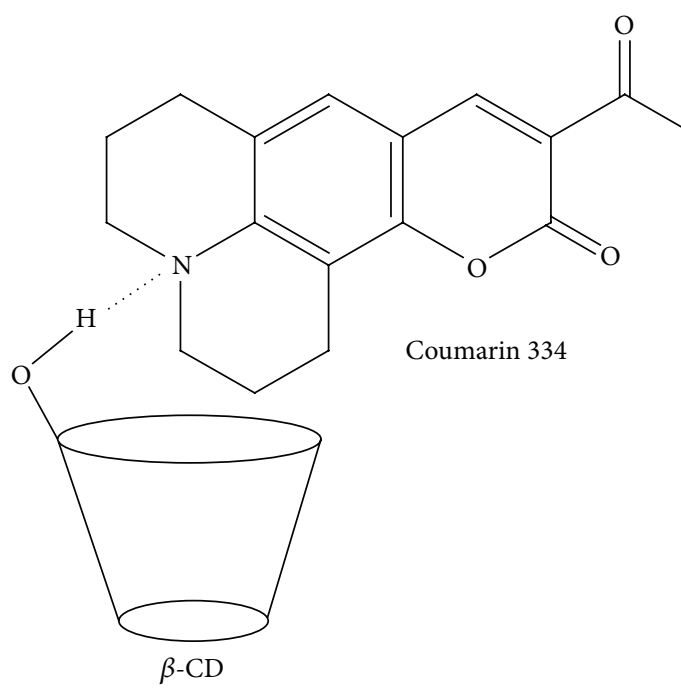

(a)

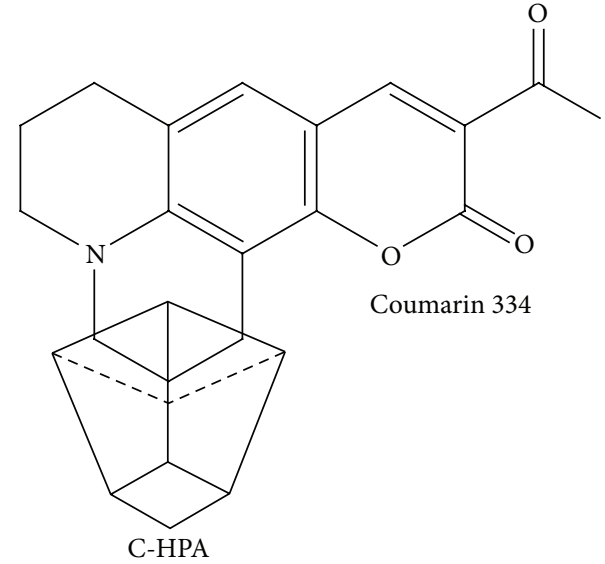

(b)

FIgURE 12: Schematic picture of the interaction of C334 with $\beta$-CD and with C-HPA.

a binding constant of $9.5 \times 10^{5} \mathrm{~mol}^{-1} \mathrm{dm}^{3}$, calculated from the Benesi-Hildebrand equation for the absorption of C334C-HPA complex. NMR spectral evidences implied that the hexahydroquinoline ring of $\mathrm{C} 334$ bound with C-HPA. The calculated $p K_{a}$ for the neutral-cation equilibrium of C334 in water is 0.42 , and the excited state $p K_{a}$ value was 0.4 . This value was similar to the ground state $p K_{a}$ value, and hence, the prototropic equilibrium might be attained in the ground state itself and was unaltered in the excited state. The monocation formation might be hindered due to the pronounced hydrogen bonding interaction between the hydroxyls of $\beta-C D$ and the fluorophore. The $p K_{a}^{*}$ could not be calculated for the neutral-cation equilibrium in the presence of C-HPA, as the complexation of C-HPA hindered protonation of the guest molecule.

\section{Conflict of Interests}

The authors declare that they have no conflict of interests.

\section{Acknowledgment}

The authors are sincerely thankful to the Department of Science and Technology; SERB, Government of India, for the funding of the project SR/FT/CS-062/2009.

\section{References}

[1] J. R. Sheats and P. F. Barbara, "Molecular materials in electronic and optoelectronic devices," Accounts of Chemical Research, vol. 32, no. 3, pp. 191-192, 1999.

[2] H. Pal, S. Nad, and M. Kumbhakar, "Photophysical properties of coumarin-120: unusual behavior in nonpolar solvents," Journal of Chemical Physics, vol. 119, no. 1, pp. 443-452, 2003.

[3] M. Kumbhakar, S. Nath, T. Mukherjee, and H. Pal, "Intermolecular electron transfer between coumarin dyes and aromatic amines in Triton-X-100 micellar solutions: evidence for Marcus inverted region," Journal of Chemical Physics, vol. 120, no. 6, pp. 2824-2834, 2004.

[4] E. W. Castner Jr., D. Kennedy, and R. J. Cave, "Solvent as electron donor: donor/acceptor electronic coupling is a dynamical variable," The Journal of Physical Chemistry A, vol. 104, no. 13, pp. 2869-2885, 2000.

[5] A. Morandeira, A. Fürstenberg, and E. Vauthey, "Fluorescence quenching in electron-donating solvents. 2. Solvent dependence and product dynamics," The Journal of Physical Chemistry A, vol. 108, no. 40, pp. 8190-8200, 2004.

[6] S. Nad and H. Pal, "Photoinduced electron transfer from aliphatic amines to coumarin dyes," Journal of Chemical Physics, vol. 116, no. 4, pp. 1658-1670, 2002.

[7] G. Jones II, W. R. Jackson, C. Choi, and W. R. Bergmark, "Solvent effects on emission yield and lifetime for coumarin laser dyes. Requirements for a rotatory decay mechanism," The Journal of Physical Chemistry, vol. 89, no. 2, pp. 294-300, 1985.

[8] K. Rechthaler and G. Köhler, "Excited state properties and deactivation pathways of 7-aminocoumarins," Chemical Physics, vol. 189, no. 1, pp. 99-116, 1994.

[9] M. El-Kemary and W. Rettig, "Multiple emission in coumarins with heterocyclic substituents," Physical Chemistry Chemical Physics, vol. 5, no. 23, pp. 5221-5228, 2003.

[10] A. Barik, S. Nath, and H. Pal, "Effect of solvent polarity on the photophysical properties of coumarin-1 dye," Journal of Chemical Physics, vol. 119, no. 19, pp. 10202-10208, 2003.

[11] S. Nad, M. Kumbhakar, and H. Pal, "Photophysical properties of coumarin-152 and coumarin-481 dyes: unusual behavior in nonpolar and in higher polarity solvents," The Journal of Physical Chemistry A, vol. 107, no. 24, pp. 4808-4816, 2003.

[12] S. Senthilkumar, S. Nath, and H. Pal, "Photophysical properties of coumarin-30 dye in aprotic and protic solvents of varying polarities," Photochemistry and Photobiology, vol. 80, no. 1, pp. 104-111, 2004.

[13] G. Jones II and J. A. C. Jimenez, "Azole-linked coumarin dyes as fluorescence probes of domain-forming polymers," Journal 
of Photochemistry and Photobiology B, vol. 65, no. 1, pp. 5-12, 2002.

[14] G. Jones II and J. A. C. Jimenez, "Intramolecular photoinduced electron transfer for cations derived from azole-substituted coumarin dyes," Tetrahedron Letters, vol. 40, no. 49, pp. 85518555, 1999.

[15] U. S. Raikar, C. G. Renuka, Y. F. Nadaf, B. G. Mulimani, A. M. Karguppikar, and M. K. Soudagar, "Solvent effects on the absorption and fluorescence spectra of coumarins 6 and 7 molecules: determination of ground and excited state dipole moment," Spectrochimica Acta A, vol. 65, no. 3-4, pp. 673-677, 2006.

[16] D. Avnir, D. Levy, and R. Reisfeld, "The nature of the silica cage as reflected by spectral changes and enhanced photostability of trapped rhodamine 6G," The Journal of Physical Chemistry, vol. 88, no. 24, pp. 5956-5959, 1984.

[17] D. Avnir, V. R. Kaufman, and R. Reisfeld, "Organic fluorescent dyes trapped in silica and silica-titania thin films by the solgel method. Photophysical, film and cage properties," Journal of Non-Crystalline Solids, vol. 74, no. 2-3, pp. 395-406, 1985.

[18] J. S. S. de Melo, R. S. Becker, and A. L. Maçanita, "Photophysical behavior of coumarins as a function of substitution and solvent: experimental evidence for the existence of a lowest lying $1\left(\mathrm{n}, \pi^{*}\right)$ state," The Journal of Physical Chemistry, vol. 98, no. 24, pp. 6054-6058, 1994.

[19] W. Rettig and A. Klock, "Intramolecular fluorescence quenching in aminocoumarines. Identification of an excited state with full charge separation," Canadian Journal of Chemistry, vol. 63, pp. 1649-1653, 1985.

[20] R. S. Moog, W. W. Davis, S. G. Ostrowski, and G. L. Wilson, "Solvent effects on electronic transitions in several coumarins," Chemical Physics Letters, vol. 299, no. 3-4, pp. 265-271, 1999.

[21] B. Raju B. and T. S. Varadarajan, "Substituent and solvent effects on the twisted intramolecular charge transfer of three new 7(diethylamino)coumarin-3-aldehyde derivatives," The Journal of Physical Chemistry, vol. 98, no. 36, pp. 8903-8905, 1994.

[22] D. Egan, R. O'Kennedy, E. Moran, D. Cox, E. Prosser, and R. D. Thornes, "The pharmacology, metabolism, analysis, and applications of coumarin and coumarin-related compounds," Drug Metabolism Reviews, vol. 22, no. 5, pp. 503-529, 1990.

[23] J. Aaron, M. Buna, C. Parkanyi, M. S. Antonious, A. Tine, and L. Cisse, "Quantitative treatment of the effect of solvent on the electronic absorption and fluorescence spectra of substituted coumarins: evaluation of the first excited singlet-state dipole moments," Journal of Fluorescence, vol. 5, no. 4, pp. 337-347, 1995.

[24] J. Shobini, A. K. Mishra, K. Sandhya, and N. Chandra, "Interaction of coumarin derivatives with human serum albumin: investigation by fluorescence spectroscopic technique and modeling studies," Spectrochimica Acta A, vol. 57, no. 5, pp. 1133-1147, 2001.

[25] H. P. Rang, M. M. Dale, and J. Ritter, Molecular Pharmacology, Churchill Livingstone, New York, NY, USA, 3rd edition, 1995.

[26] G. A. Reynolds and K. H. Drexhage, "New coumarin dyes with rigidized structure for flashlamp-pumped dye lasers," Optics Communications, vol. 13, no. 3, pp. 222-225, 1975.

[27] C. Jullian, L. Moyano, C. Yañez, and C. Olea-Azar, "Complexation of quercetin with three kinds of cyclodextrins: an antioxidant study," Spectrochimica Acta A, vol. 67, no. 1, pp. 230234,2007

[28] D. Haiyun, C. Jianbin, Z. Guomei, S. Shaomin, and P. Jinhao, "Preparation and spectral investigation on inclusion complex of $\beta$-cyclodextrin with rutin," Spectrochimica Acta A, vol. 59, no. 14, pp. 3421-3429, 2003.

[29] M. V. Enoch, R. Rajamohan, and M. Swaminathan, "Fluorimetric and prototropic studies on the inclusion complexation of $3,3^{\prime}$-diaminodiphenylsulphone with $\beta$-cyclodextrin and its unusual behavior," Spectrochimica Acta A, vol. 77, no. 2, pp. 473$477,2010$.

[30] Y. Sameena, Devi Radhika, I. V. M. V. Enoch, and E. Murugesh, "The influence of $\beta$-cyclodextrin encapsulation on the binding of $2^{\prime}$-hydroxyflavanone with calf thymus DNA," Spectrochimica Acta A, vol. 98, pp. 405-412, 2012.

[31] X. Liu, Y. Liu, G. Li, and R. Warmuth, "One-pot, 18-component synthesis of an octahedral nanocontainer molecule," Angewandte Chemie-International Edition, vol. 45, no. 6, pp. 901904, 2006.

[32] L. R. MacGillivray and J. L. Atwood, "A chiral spherical molecular assembly held together by 60 hydrogen bonds," Nature, vol. 389, no. 6650, pp. 469-472, 1997.

[33] H. Wang and N. Shao, "Host-guest chemistry of dendrimercyclodextrin conjugates: selective encapsulations of guests within dendrimer or cyclodextrin cavities revealed by NOE NMR techniques," The Journal of Physical Chemistry B, vol. 116, no. 36, pp. 11217-11224, 2012.

[34] G. W. V. Cave, J. Antesberger, L. J. Barbour, R. M. McKinlay, and J. L. Atwood, "Inner core structure responds to communication between nanocapsule walls," Angewandte ChemieInternational Edition, vol. 43, no. 39, pp. 5263-5266, 2004.

[35] J. Szejtli, Cyclodextrins and Their Inclusion Complexes, Academic Kiado, Budapest, Hungary, 1982.

[36] O. Stern and M. Volmer, "Über die Abklingzeit der Fluoreszenz," Physikalische Zeitschrift, vol. 20, pp. 183-188, 1919.

[37] J. G. Calvert and J. N. Pitts, Photochemistry, John Wiley \& Sons, New York, NY, USA, 1966.

[38] A. Douhal, Cyclodextrin Materials Photochemistry, Photophysics and Photobiology, vol. 1, Elsevier, Amsterdam, The Netherlands, 2006.

[39] P. Debye and E. Hückel, "Theory of electrolytes-part II: law of the limit of electrolytic conduction," Physikalische Zeitschrift, vol. 24, pp. 305-325, 1923. 

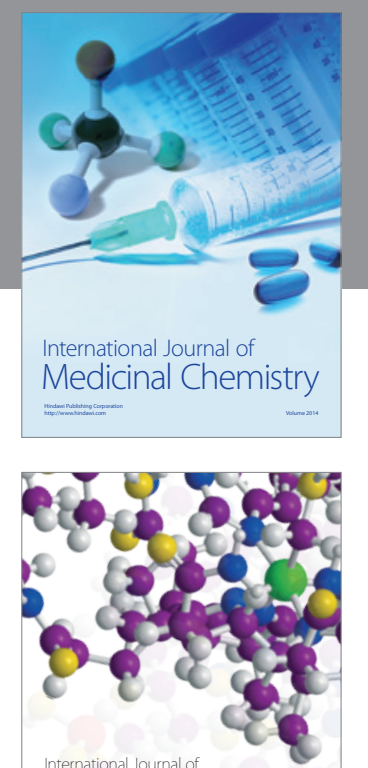

\section{Carbohydrate} Chemistry

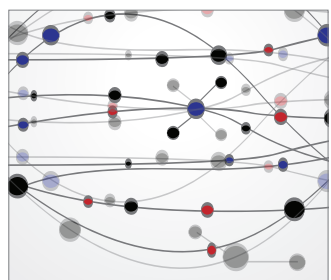

The Scientific World Journal
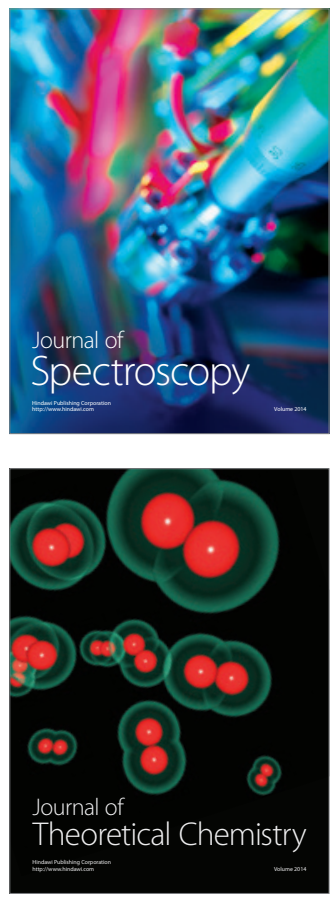
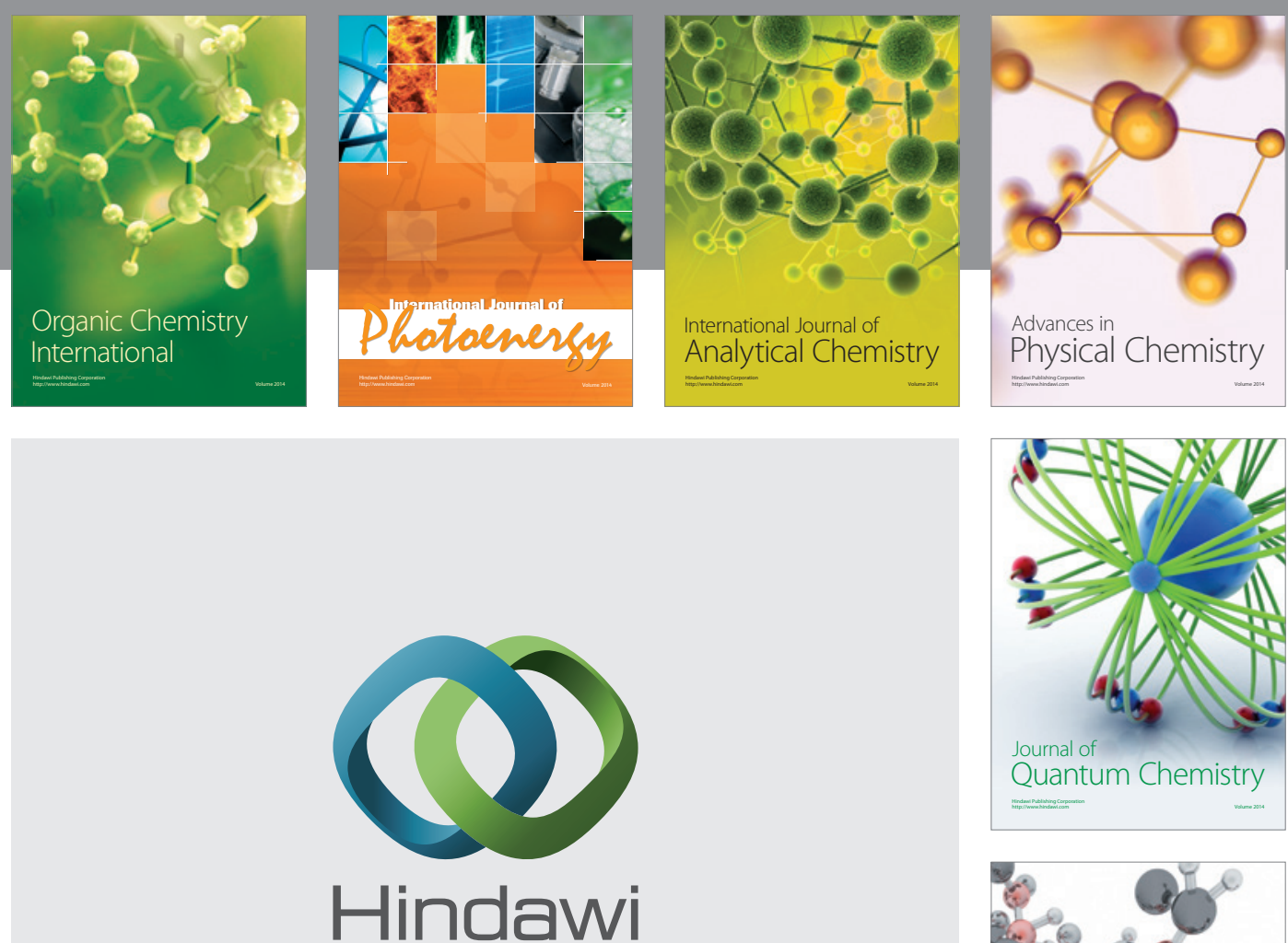

Submit your manuscripts at

http://www.hindawi.com

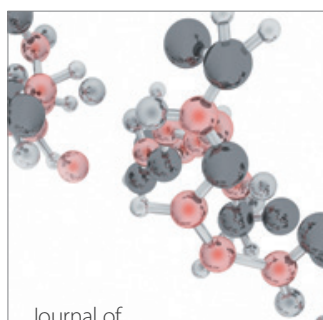

Analytical Methods

in Chemistry

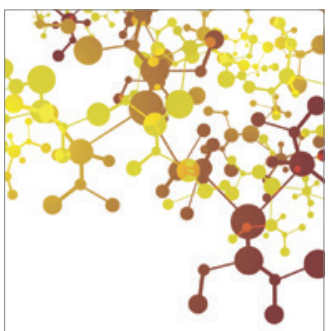

Journal of

Applied Chemistry

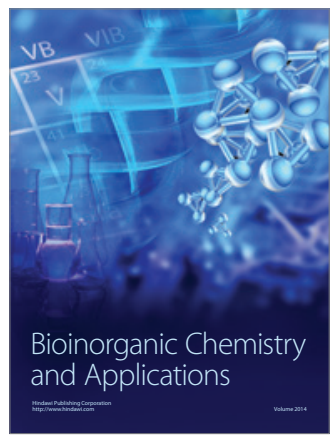

Inorganic Chemistry
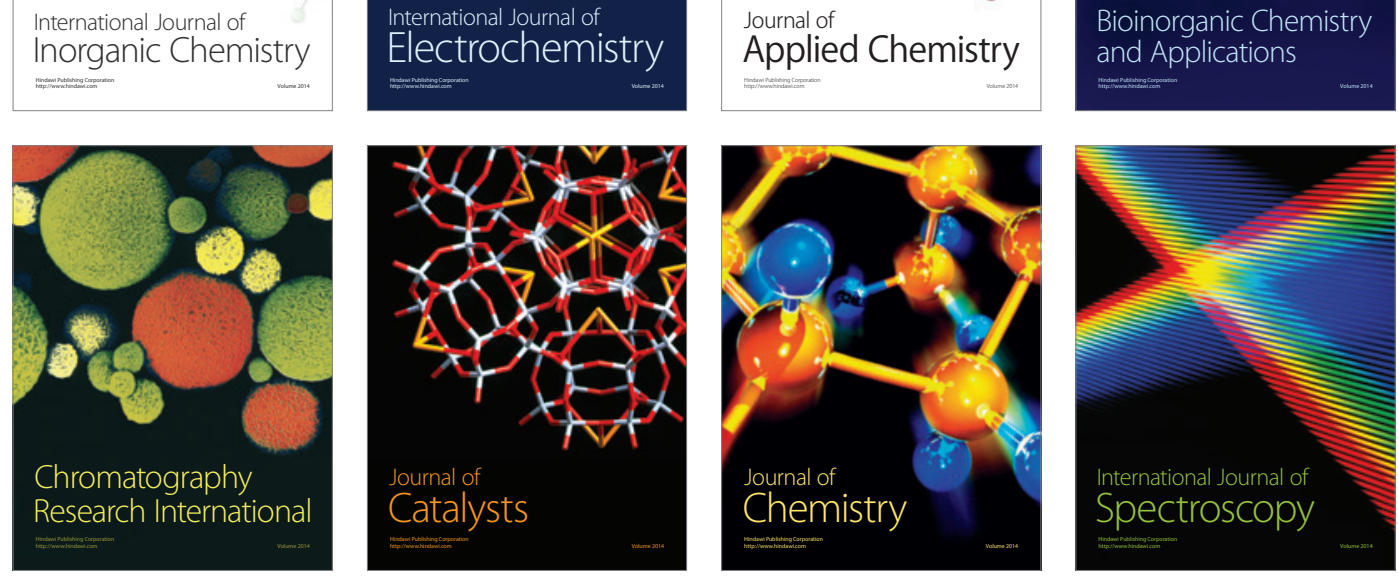